\title{
COMPARISON OF THREE SAMPLING METHODS OF MAN-BITING ANOPHELINES IN ORDER TO ESTIMATE THE MALARIA TRANSMISSION in a Village of South Cameroon
}

\author{
LE GOFF G., CARNEVALE P., FONDJO E. \& ROBERT V.*
}

Summary :

In order to get an accurate measure of malaria transmission by mean of human bait attraction, three methods of catches for human-bait mosquitoes were compared in a Cameroonian village of high anopheline density. These three methods were 1) the classical human landing catches where the man was in the same time bait and catcher, 2) the single-nets which acted as a trap and 3) the double-nets where the outer net acted as a trap and the inner avoided mosquito bites. The anopheline densities per man with human landings were 1.6 time higher than those obtained with single-nets, these later being 4.7 times higher than those obtained with double-nets. In the three methods, the results were similar for the anophelines species catched and for their respective proportions. The samples of Anopheles nili and An. gambiae had comparative parity rates and sporozoitic indexes. From these results, in order to estimate the malaria transmission it can be envisaged to change the standard human-bait catch for the human-baited single bed-net catch; on the contrary the double-net have to be discarded because of their poor results.

KEY WORDS : malaria, measure of transmission, anopheline, sampling, comparison, South Cameroon.
Résumé : COMPARAISON DE TROIS MÉTHODES D'ÉCHANTILLONNAGE D'ANOPHĖLES AGRESSIFS POUR L'HOMME AFIN D'ÉVALUER LA TRANSMISSION Du paludisme dans un VILlage du Sud Cameroun

Dans le but d'obtenir une mesure correcte de la transmission du paludisme en utilisant une technique entomologique classique, trois méthodes de capture de moustiques agressits pour l'homme ont été comparées dans un village camerounais de haute densité anophélienne. II s'agit de 1) la classique capture sur l'homme où celvi-ci est à la fois appât et captureur, 2) la moustiquaire simple qui agit comme un piège, 3) la moustiquaire double où la moustiquaire extérieure agit comme un piège et la moustiquaire interne empêche les piqûres de moustiques. Les densités anophéliennes, évaluées par homme-nuit ont été 1,6 fois plus élevées dans les captures directes sur hommes que celles obtenues sous les simples moustiquaires, celles-ci étant 4,7 fois plus élevées que celles obtenues sous les doubles moustiquaires. Avec les trois méthodes, les espèces anophéliennes capturées ont été identiques; leurs proportions respectives ont été comparables. Les Anopheles nili et An. gambiae ont présenté des taux de parturité et des indices sporozoitiques comparables. A partir de ces résultats, pour estimer la transmission du paludisme, on peut envisager de remplacer la classique capture sur homme par la méthode de la simple moustiquaire; par contre la méthode de la double moustiquaire reste trop peu efficace.

MOTS CLÉS : paludisme, mesure de la transmission, anophèles, échantillonnage, comparaison, Sud Cameroun.

\section{INTRODUCTION}

M any methods are available nowadays for sampling culicine populations (Service, 1993), each of them offering benefits and disadvantages. Selecting one of them depends on what the study aims, the available methods, the local ecological conditions.

To get a good view of the vector-borne disease transmission, the entomologist must select a catching method that meets a main requirement: get the best

\footnotetext{
* Institut français de recherche scientifique pour le développement en coopération (ORSTOM), Organisation de Coordination pour la lutte contre les Grandes Endémies en Afrique Centrale (OCEAC), BP 288, Yaoundé, Cameroun.

Correspondance: Vincent Robert. Laboratoire de Paludologie, BP 1386, Dakar, Sénégal.

E-mail: robert@belair.orstom.sn
}

evaluation of host/infective vectors relationships in a given situation.

Regarding human malaria transmission, people serving both as baits and collectors has up to now been considered as the reference (World Health Organisation, 1975). Indeed this method has the advantages at first, of selecting right away the anthropophilic anopheline species which is the only one which interests malaria transmission, and second, to assign catched mosquitoes directly to one man. With an attentive catcher, many mosquitoes are catched before they probe, but unfortunately some of them succeed to feed.

In area of malaria transmission, for obvious ethical principles, another technique should be wished to prevent the collector from being bitten while the results remain as reliable as possible. It was considered that the human-baited double-net could be a possible alternative (Gater, 1935; Coless, 1959). 
This study aims to compare the man-seeking anopheline populations sampled according to the three following methods which allow to maintain mosquitoes alive:

- stationary direct human landing catches, considered here as the reference method, where men served both as bait and collector;

- human-baited single bed-net catches, where men served as bait while they were not protected from mosquito bites;

- human-baited double bed-net catches, where men served as bait and were not bitten.

The host-seeking anopheline density per man, the physiological age of the populations, and the proportion of Plasmodium sporozoites infected Anopheles were measured and discussed in the view of estimating the malaria transmission.

\section{MATERIALS AND METHODS}

S tudy area: The study was carried out in Mbebe, a traditional south Cameroonian forest village $\left(4^{\circ} \mathrm{N}, 11^{\circ} \mathrm{E}\right)$. This village consisted of three hamlets located on the west bank of the Sanaga River mean section. The study took place at night, according to the customary host-seeking habits of the malaria vectors.

Human landing catches: In the human landing catches the catcher worked indoors, sitting on a low chair with his legs bare. Supplied with a flash-light which he turned on now and then, he trapped the alighted mosquitoes into a haemolysis tube which he blocked up at once. Two teams of catchers were used: the first one from $20 \mathrm{~h}$ till $1 \mathrm{~h}$, and the second one from $1 \mathrm{~h}$ till $6 \mathrm{~h}$.

Single-net catches : In the single-net catches the collector lied on a bed, sleeping at will. A bed-net of $1.4 \mathrm{~m}$ high, $1.6 \mathrm{~m}$ long and $0.7 \mathrm{~m}$ wide, i.e. $1.6 \mathrm{~m}^{3}$, was put into place all around him by means of a frame attached to his bed. One side of the bed-net was put up on about $10 \mathrm{~cm}$ hight and $1 \mathrm{~m}$ long to provide an entry to the mosquitoes averaging $1.5 \%$ of the total area. At $1 \mathrm{~h}$ and, at the end of the night, the mosquitoes trapped into the bed-net were gathered with a mouth vacuum-cleaner by the collector.

Double-net catches: In the double-net catches (Coless, 1959), a device similar to single-net but kept totally closed was covered entirely by a bigger bed-net, $1.8 \mathrm{~m}$ high, $2 \mathrm{~m}$ long, and $1.5 \mathrm{~m}$ large, i.e. $15.6 \mathrm{~m}^{2}$ and $5.4 \mathrm{~m}^{3}$. One side of this outer bed-net was put up on about $10 \mathrm{~cm}$ high and $1 \mathrm{~m}$ long. The mosquitoes were collected at $1 \mathrm{~h}$ and $5 \mathrm{~h}$ in the space between the two bed-nets.

People involved in the study: Everybody was volunteer. A chemoprophylaxis was proposed and a clinical follow up was carried out during the whole study. To avoid any individual attractiveness interfered with the results, a turn-over of the volunteers was systematically established in the various houses and rooms.

\section{RESULTS}

\section{COMPARISON BETWEEN HUMAN LANDING AND SINGLE-NET CATCHES}

1 he study lasted six months from April to September 1989 and occurred during three nights each month, therefore 18 nights in total. One night-collection concerned four houses per hamlet each month, i.e. 12 men-nights per month for either means of catches. Both methods were running from $20 \mathrm{~h}$ till $6 \mathrm{~h}$ in two different bedrooms within the same house.

Culicidian genera : During human landing catches, 70 men-nights catched 2,227 mosquitoes. Under singlenets 68 men-nights allowed 1,316 mosquitoes to be collected. The ratio of human landing catches in comparison with single-net catches was 1.64 for the mosquitoes collected.

A large majority (97.6\%) of the mosquitoes collected during human landing catches belonged to the Anopheles genus, and $2.4 \%$ to the Culicinae sub-family with $2 \%$ to the Mansonia genus. In single-net catches $99.5 \%$ of the mosquitoes belonged to the Anopheles genus, and $0.5 \%$ to the Culicinae sub-family (Table I). Although the difference between these percentages was low, the distribution of the Anopheles between these two methods of catches differed significantly $\left(\chi^{2}=17.5, \mathrm{P}<10^{-4}\right)$. The ratio of human landing catches compared with single-net catches was 1.61 for the Anopheles genus.

Anopheline species : 260 An. gambiae, 1,900 An. nili and 13 An. funestus were collected with human landing catches, i.e. $12 \%, 87.4 \%$ and $0.6 \%$ of the Anopheles respectively. With single-nets, 152 An. gambiae, 1,143 An. nili and 14 An. funestus were collected, i.e. $11.6 \%$, $87.3 \%$ and $1.1 \%$ of the Anopheles. The ratio of the human landing collections compared with the singlenet collections for the two most represented anopheline species were 1.66 for An. gambiae and 1.61 for $A n$. nili. 


\begin{tabular}{lcr}
\hline Method of catching & Human landing & Single-net \\
\hline Number of man night & 70 & 68 \\
\hline Anopheles gambiae & $260-(11.7 \%)$ & $152-(11.6 \%)$ \\
Anopheles nili & $1,900-(85.3 \%)$ & $13-(0.6 \%)$ \\
Anopheles funestus $\quad$ & $14-(1.1 \%)$ \\
$\quad$ Total Anophelinae & $2,173-(97.6 \%)$ & $1,309-(99.5 \%)$ \\
\hline Mansonia africana and $M$. uniformis & $45-(2 \%)$ & $6-(0.4 \%)$ \\
Culex gr. decens & $4-(0.2 \%)$ & $1-(0.1 \%)$ \\
Aedes vittatus & $3-(0.1 \%)$ & $0-(0 \%)$ \\
$\quad$ Tedomya furfurea & $2-(0.1 \%)$ & $0-(0 \%)$ \\
\hline Total Culicinae & $54-(2.4 \%)$ & $7-(0.5 \%)$ \\
\hline
\end{tabular}

Table I. - Number of mosquitoes collected in human landing catches and human baited single-net catches from April to September 1989 in the Mbebe area (South Cameroon).

Parous rates: The parous rates of the An. gambiae collected was of $69.7 \%$ with human landing catches and $57.9 \%$ with single bed-nets (Table II); the difference was significant $\left(\chi^{2}=4.99, \mathrm{P}=0.025\right)$. In each hamlet the parous rates of the An. gambiae were higher on men than under single-nets: $75 \%$ versus $62 \%, 62 \%$ versus $56 \%$, and $76 \%$ versus $55 \%$. The difference was significant for only one of the hamlets. During each of the first three months, when the number of individuals collected was sufficient, the parous rates of the An. gambiae were higher on men than under single-nets; the difference was significant for the sole month of May.

The parous rate of the An. nili catched with human landing catches was of $66.2 \%$ and $74.6 \%$ for those collected with single bed-nets. The difference in the distribution of the two samples was significant $\left(\chi^{2}=22.6, \mathrm{P}<10^{-5}\right)$. As far as each of these hamlets was considered this difference remained significant for only two of them. The parous rates of the samples collected on man were always lower than of those collected under single-nets, either hamlet by hamlet or month by month except for the month of April: $76 \%$ versus $74 \%$. In a month by month analysis this difference was significant only for both August and September, when $A n$. nili densities were very high and parous rates at their lowest. The ratio of human landing catches on single-nets collections was at its highest when the physiological age of the An. nili population was young: in July, the parous rate of the An. nili sampled with single bed-net collections was $83.4 \%$ with a $1.24 \mathrm{man} /$ single-net ratio ; in August the parous rate was $56.3 \%$ and the ratio 2.35 (Fig. 1).

Seven out of 10 An. funestus caught on man, and 10 out of 12 under single-nets were parous. There was no significant difference between the two samples $\left(\chi^{2}=0.17, P=0.683\right)$.

Sporozoite indexes: The sporozoite indexes of the Anopheles caught on man and under single-nets were of: $2.88 \%$ and $5 \%$ for An. gambiae, $0.75 \%$ and $0.90 \%$ for An. nili and of $1 / 12$ and 1/11 for An. funestus. None of these differences was significant, either for $A n$. gambiae $\left(\chi^{2}=1.13, \mathrm{P}=0.283\right)$, or An. nili $\left(\chi^{2}=0.17\right.$, $\mathrm{P}=0.681$ ), or An. funestus (Fisher exact unilateral probability, $\mathrm{P}=0.75$ ).

\begin{tabular}{|c|c|c|c|c|c|c|}
\hline \multirow[b]{2}{*}{ Method of catching } & \multicolumn{2}{|c|}{ Anopheles gambiae } & \multicolumn{2}{|c|}{ Anopheles nili } & \multicolumn{2}{|c|}{ Anopheles funestus } \\
\hline & $\mathrm{HL}$ & $\mathrm{S}-\mathrm{N}$ & $\mathrm{HL}$ & $\mathrm{S}-\mathrm{N}$ & $\mathrm{HL}$ & S-N \\
\hline $\begin{array}{l}\text { Parous } \\
\text { Nulliparous } \\
\text { Parous rate }\end{array}$ & $\begin{array}{c}161 \\
70 \\
69.7 \%\end{array}$ & $\begin{array}{c}73 \\
53 \\
57.9 \%\end{array}$ & $\begin{array}{c}1163 \\
595 \\
66.2 \%\end{array}$ & $\begin{array}{c}798 \\
271 \\
74.6 \%\end{array}$ & $\begin{array}{r}10 \\
2\end{array}$ & $\begin{array}{c}7 \\
3 \\
-\end{array}$ \\
\hline $\begin{array}{l}\text { No. dissected } \\
\text { Positive } \\
\text { Sporozoite index }\end{array}$ & $\begin{array}{c}243 \\
7 \\
2.88 \%\end{array}$ & $\begin{array}{c}140 \\
7 \\
5.00 \%\end{array}$ & $\begin{array}{c}1594 \\
12 \\
0.75 \%\end{array}$ & $\begin{array}{c}998 \\
9 \\
0.90 \%\end{array}$ & $\begin{array}{r}12 \\
1 \\
-\end{array}$ & $\begin{array}{r}11 \\
1 \\
-\end{array}$ \\
\hline
\end{tabular}

Table II. - Results of the dissection of the anopheline collected in human landing catches (HL) and human baited single-net catches (S-N) from April to September 1989 in the Mbebe area (South Cameroon). 


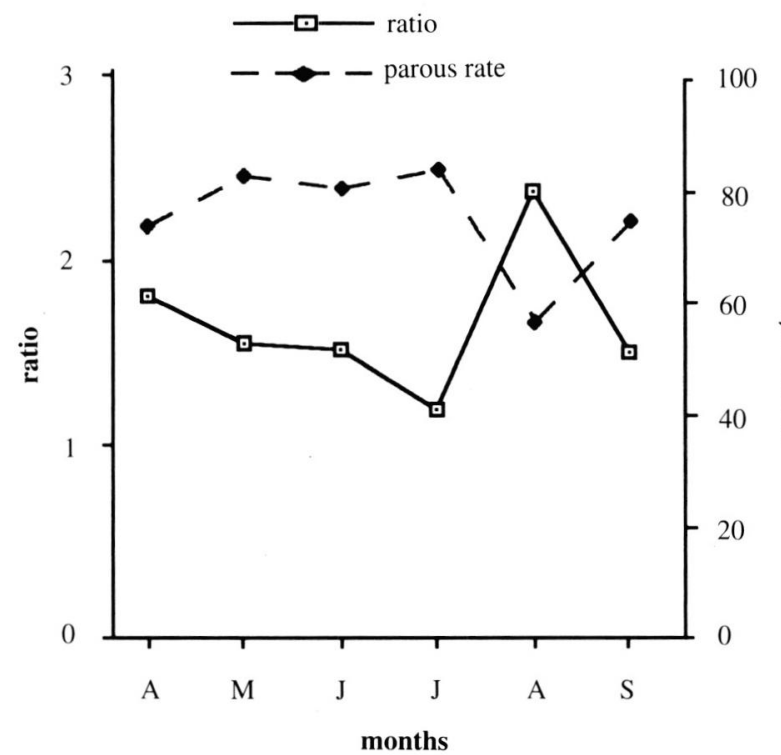

Fig. 1. - Evolutions for An. nili of the ratio human landing/singlenet catches and the parous rate in single-net catches.

Transmission rate estimation: During the six month' period of observation the inoculation rate was 62 infective bites per man with human landing catches and 51 with single-net catches. There was no difference in the distribution of the vector species in both methods, An. nili being the main vector species. The monthly evolution of the inoculation rate was comparable by the two methods (Table II). The transmission due to $A n$. nili was observed each month with the human landing catches but not in April, May and September with the single-nets (Fig. 2). Due to the absence of salivary glands positive for sporozoites with single-nets in September, the inoculation rate was none during this month.

\section{COMPARISON BETWEEN SINGLE-NET AND DOUBLE-NET CATCHES}

The study lasted six months, from August 1988 to January 1989 and occurred during three nights each month, therefore 18 nights in total. One night-collection was performed by four sleepers in four different bedrooms belonging to four different houses within a single hamlet. Two persons slept under single-nets and two others under double-nets from $21 \mathrm{~h}$ till $5 \mathrm{~h}$.

Culicidian genera: With single-nets, 38 man-nights collected 1,007 mosquitoes whereas 36 man-nights with double-nets caught 238 mosquitoes (Table III). Thus the ratio of single-net on double-net collections was 4.01 .

With single-nets, $89.9 \%$ of the mosquitoes collected belonged to Anopheles, and $10.1 \%$ to Mansonia. With
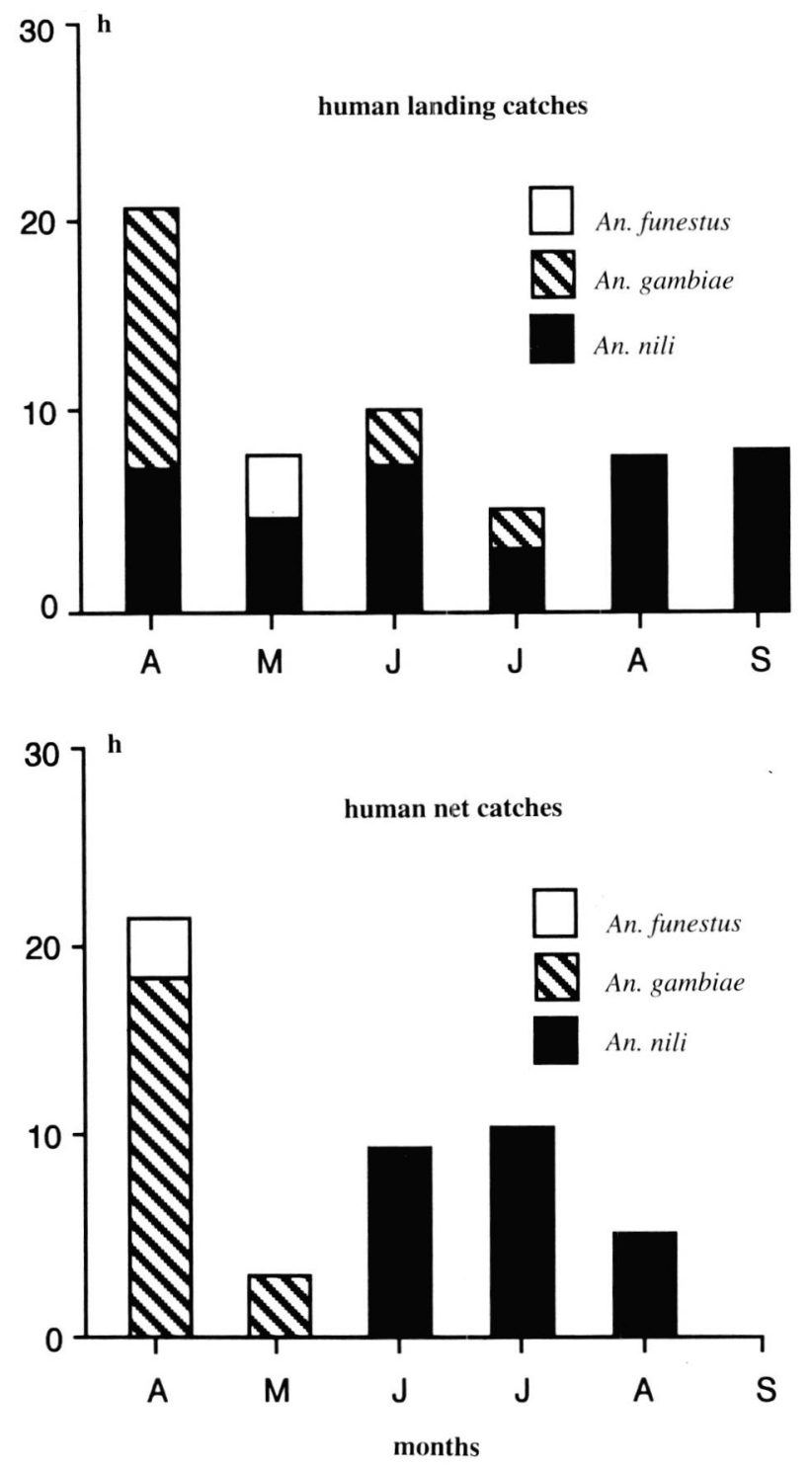

Fig. 2. - Evolution of the monthly inoculation rate (h) with two methods.

double-nets $77.3 \%$ belonged to the Anopheles, $20.2 \%$ to Mansonia and $2.5 \%$ to Culex. The ratio of singlenet on double-net collections was noticeably higher for Anopheles (4.66) than for Mansonia (2.01).

Anopheline species: The species distribution within the Anopheles genus was the same by the two methods. $4.2 \%$ of An. gambiae, $95.7 \%$ of An. nili and $0.1 \%$ of $A n$. funestus were caught with single-nets, compared with $3.8 \%, 96.2 \%$ and $0.0 \%$ with doublenets. An. nili was the most frequently caught culicidian species and represented $86 \%$ and $74 \%$ respectively of the whole collections. Ratio of single-net on doublenet collections was about the same for $A n$. gambiae (5.14) and An. nili (4.64). 


\begin{tabular}{|c|c|c|}
\hline Method of catching & Single-net & Double-net \\
\hline Number of man night & 38 & 36 \\
\hline Anopheles gambiae & $38-(3.8 \%)$ & $7-(2.9 \%)$ \\
\hline Anopheles nili & $866-(86 \%)$ & $177-(74.4 \%)$ \\
\hline Anopheles funestus & 1-(0.1\%) & $0-(0 \%)$ \\
\hline Total Anophelinae & $905-(89.9 \%)$ & $184-(77.3 \%)$ \\
\hline Mansonia africana and $M$. uniformis & $102-(10.1 \%)$ & $48-(20.2 \%)$ \\
\hline Culex gr. decens & $0-(0 \%)$ & $6-(2.5 \%)$ \\
\hline Total Culicinae & $102-(10.1 \%)$ & $54-(22.7 \%)$ \\
\hline Total Culicidae & $1,007-(100 \%)$ & $238-(100 \%)$ \\
\hline
\end{tabular}

Table III. - Number of mosquitoes collected under single and double-net from August 1988 to January 1989 in the Mbebe area (South Cameroon).

Parous rates: An. nili parous rates were quite comparable by the two methods: 646 parous/142 nulliparous with single-nets (82\%) and 142 parous/31 nulliparous with double-nets (82\%). The number of An. gambiae collected was too small to be exploited.

Sporozoite indexes and transmission rate: With singlenets, none of the 44 An. gambiae and two of the 230 dissected An. nili harboured sporozoites in their salivary glands. The two positive specimens came from one single-net collection. With the double-nets no positive mosquito was observed among 80 dissected. The difference was non-significant (Fisher unilateral exact probability $\mathrm{P}=0.55$ ). In terms of transmission the small number of mosquitoes collected with doublenets did not allow further comparisons.

\section{DISCUSSION}

$\mathrm{T}$ he ratio of human landing catches compared with single-net catches was approximately 1.6 for the Anopheles genus. This ratio remained remarkably stable for the two most widely represented anopheline species; similar results were reported by Service (1969). The single-nets catched 4.7 times more of Anopheles than the double-nets. This ratio was two for the Mansonia genus.

There was constancy in the relative proportions of An. gambiae, An. nili and An. funestus whatever means of catching was used.

For An. gambiae and An. nili, the samples collected from human landing catches and single-net catches seemed comparable. Still, when the parous rates of the mosquitoes collected from human landing catches were compared with the single-net catches ones, they were $12 \%$ higher for An. gambiae and $9 \%$ lower for
An. nili. These significant differences remained moderate and confusing to explicite.

The performances of the single-net changed according to the parous rates of the An. nili populations, with collection increasing when the parous rate decreased. Such a phenomenon could be related to the lower ability of the nulliparous to fly, which might hindered their entrance into the net.

Samples of An. nili collected from single and doublenet collections did not show any significant difference, the physiological age particularly being identical.

These results prompted us to believe that all the anopheline samples obtained from the various means of catches were reliable to a single population (BaillyChoumara, 1973). Such an observation could be expected due to the three methods baited by men.

The inoculation rate did not differ much between human landing and single-net catches. The monthly variations of the transmission showed a similar course by the two methods. The main difference observed occurred in the permanence of transmission with An. nili which was not observed with the single-net. This lack of sensitivity in the single-net catches to detect malaria transmission was probably related to its lower performance.

In human landing catches a succession of two awaken collectors was needed throughout the night to give information on the whole night whereas single-net catches took only one person by net, who ordinary slept.

On average one double-net trapped four times less mosquitoes than one single-net (Rubio-Palis \& Curtis, 1992) and about 7.5 times less than one catching man. A great number of mosquitoes most probably escaped from the outer net (Coless, 1959; Hamon, 1964). Possible improvement might be tried by setting flaps into the outer net in order to prevent the mosquitoes from escaping. Improvements were proposed between inner 
and outer nets with an inverted CDC light-trap (Charlwood et al., 1986) or with a trap without any light which sucks mosquitoes (Mutero \& Birley, 1987). However, important sophistication would alter the interest of the device. Besides, the double-net proved rather cumbersome and was obviously handier in roomy places than in bedrooms.

It is concluded that these three methods catching human-seeking mosquitoes provided qualitatively comparable samples. Human landing catches and single-net catches gave comparable information on the estimation of malaria transmission. As an entomological parameter in the calculation of the inoculation rate, density by man had to be corrected with the single-net (1.6 time higher) in order to evaluate the malaria transmission. These two methods of catching did not prevent the servant from bites. The doublenet protected the servant but its performance was poor and did not permit to measure malaria transmission.

\section{ACKNOWLEDGEMENTS}

he authors thank Jean-Claude Toto for the work in the field. This study was supported by the Institut français de recherche en coopération pour le développement (ORSTOM), by the Organisation de Coordination pour la lutte contre les Endémies en Afrique Centrale (OCEAC), and by the French Ministry of Cooperation.

\section{REFERENCES}

Bailly-Choumara H. Étude comparative de différentes techniques de récolte de moustiques adultes (Diptera Culicidae) faite au Maroc, en zone rurale. Bulletin de la Société de Science naturelle et physique du Maroc, 1973, 53, 135187.

BIDLINGMAYER W.L. A comparaison of trapping methods for adult mosquitoes: species response and environmental influence. Journal of Medical Entomology, 1967, 4, 200220 .

Bradley G.H., Goodwin M.H. \& Stone A. Entomologic technics as applied to anophelines, p. 331-378, in: Malariology, vol. I, 1949, M. F. Boyd (ed.), W. B. Saunders Co., Pliladelphia \& London 787 p.

Charlwood J.D., Paru R. \& Dagara H. A new light-bed net trap to sample anopheline vectors of malaria in Papua, New Guinea. Bulletin of the Society of Vector Ecology, 1986, 11, 281-282.

Coless D.H. Notes on the culicine mosquitoes of Singapore. VI. Observations on catches made with baited and unbaited trap-nets. Annals of Tropical Medicine and Parasitology, 1959, 53, 251-258.
GATER B.A.R. Aids to the identification of Anopheline Imagines in Malaya. Govt. straits Settelment \& Malar. Adv. Bd., FMS, 1935, Singapore, 242 p.

HAmon J. Observations sur l'emploi des moustiquaires-pièges pour la capture semi-automatique des moustiques. Bulletin de la Société de Pathologie exotique, 1964, 57, 576-588.

Mutero C.M. \& BiRLEY M.H. Estimation of the survival rate and oviposition cycle of field populations of malaria vectors in Kenya. Journal of Applied Ecology, 1987, 24, 853863.

Rubio-Palis Y. \& CurTis C.F. Evaluation of different methods of catching anopheline mosquitoes in western Venezuela. Journal of the American Mosquito Control Association, 1992, 8, 261-267.

SERvice M.W. The use of traps in sampling mosquito populations. Entomologia experimentalis et applicata, 1969, 12, 403-412.

SERVICE M.W. Mosquito ecology: field sampling methods, Second edition. Applied Science Publishers, 1993, London, 988 p.

World Health Organization. Manual on practical entomology. Part I and II. World Health Organization, 1975, Geneva.

Reçu le 5 novembre 1996 Accepté le 13 janvier 1997 